\title{
Avaliação da concentração, distribuição de tamanho e composição química do material particulado atmosférico.
}

\author{
FOGARIN, H. M. ${ }^{1}$, COSTA, M. A.M. ${ }^{1}$, SARTI, Arnaldo ${ }^{1}$ e CARDOSO, A.A. ${ }^{2}$ \\ ${ }^{1}$ Universidade Estadual Paulista, Departamento de Bioquímica e Tecnologia Química \\ ${ }^{2}$ Universidade Estadual Paulista, Departamento de Química Analítica \\ E-mail para contato: henriquemfogarin@gmail.com
}

\begin{abstract}
RESUMO - Este trabalho apresenta análises de materiais particulados com tamanhos menores do que 2,5 $\mu \mathrm{m}$ presentes no ar atmosférico de Araraquara. $\mathrm{O}$ estudo evidenciou a relação entre temperatura, umidade relativa do ar, concentração, distribuição de tamanho do material particulado amostrado por um impactador de cascata e monitor ótico. Foi analisada a composição iônica do material particulado. A avaliação e análise de material particulado menores do que 2,5 $\mu \mathrm{m}$ é importante devido ao aumento da queima da biomassa em processos industriais como fonte de energia e também a utilização do etanol como combustível.
\end{abstract}

\section{INTRODUÇÃO}

O Brasil é atualmente o maior produtor de cana de açúcar (635 milhões de toneladas) e é responsável por um terço da colheita global, com área de 9,0 Mha de cultivo nos anos de 2014/2015, sendo que $90 \%$ do cultivo encontra-se na região centro sul (CONAB, 2015). Um adicional de 6,4 milhões de hectares de área de plantio será necessário para atender a demanda interna projetada de etanol até 2021 (61,6 bilhões L). Esta expansão significativa deve-se à crescente demanda por bioetanol, sendo considerada uma das principais causas das mudanças do uso da terra na região centro sul do Brasil, intensificando a aplicação de fertilizantes e ações antropogênicas danosas ao ambiente (Cherubin, M.R. et al. 2015). A crescente demanda de etanol associada a expansão futura projetada, o aumento do uso de fertilizantes e o excedente de bagaço da cana de açúcar produzido e cada vez mais utilizado como biocombustível originam preocupações sobre o potencial dos impactos ambientais gerados na região. A perspectiva de aumento do uso de bioenergia em muitos países tem trazido preocupações de debate internacional sobre os impactos ambientais, poluição, desmatamento e redução da biodiversidade e os problemas de saúde particularmente devido à qualidade da água e emissões de poluente para o ar (Moraes, M.A.F.D. et al. 2015). De acordo com (Urban. R.C. et. at.,2016) desde o plantio até a colheita da cana devem ser contabilizados diversos constituintes emitidos para o ambiente, como: nitrogênio, fósforo, enxofre e potássio. O nitrogênio reativo é adicionado à produção através da fertilização e retorna ao ambiente terrestre ou aquático, causando a eutrofização em lagos e rios por meio do excesso de nitrogênio, além da emissão atmosférica causando a chuva ácida através da formação de ácido nítrico e atuando como catalizador de reações atmosféricas que geram ozônio. Segundo França et al. (2012), é necessário ampliar os conhecimentos científicos sobre os impactos do crescimento da produção de etanol no Brasil e gerar inventários de gases de 
efeito estufa e emissões de aerossóis associados a esta atividade. A queima de biomassa seja ela em atividades agrícolas para facilitar a colheita com a queima das folhas externas, ou a queima do bagaço de cana de açúcar em processos industriais para geração de calor e energia, é uma importante fonte de poluentes gasosos e particulados para a atmosfera (Urban. R.C. et. at., 2016). As emissões regionais de gases e partículas em suspensão aumentaram significativamente durante o período de colheita de cana de açúcar e, consequentemente, altas concentrações de espécies orgânicas e inorgânicas foram encontradas (Allen et al., 2011). Com a implantação de leis proibitivas para a eliminação da prática da queima da palha da cana em campo se preveem uma diminuição progressiva deste processo, a eliminação da queima da palha deve ocorrer até 2021 em áreas mecanizáveis e até 2031 em áreas não mecanizáveis. Posteriormente, a União da Indústria de Cana-de-Açúcar (UNICA), representando a indústria paulista produtora de açúcar e etanol, e o Governo do Estado de São Paulo assinaram, em 2007, o protocolo no qual a eliminação da queima foi antecipada em áreas mecanizáveis para 2014 e em 2017 para outras áreas. Por outro lado, o uso do bagaço da cana de açúcar como biocombustível nas destilarias e industrias se intensificaram, e as emissões provenientes da queima deste combustível se estendem a população local, regional e global (Ibrahim Al-Naiema et al., 2015). Considerando essas atividades antrópicas e alterações, a atmosfera da região centro sul, está em um processo de mudanças de suas emissões, quantitativamente e qualitativamente, devido ao processo de colheita e uso de subprodutos da cana-de-açúcar. Com o intuito de avaliar tais mudanças, a caracterização das emissões de material particulado vem sendo e deve continuar a ser estudada para determinar sua distribuição de tamanho, concentração e a sua composição quanto a íons solúveis (Oliveira, P.L. et al., 2013). De acordo com Oliveira, P.L. et al., (2013) a variação da faixa de tamanho do material particulado relaciona-se com as diferentes fontes de emissão e sua composição química. Considera-se os processos químicos que ocorrem na atmosfera, além da combustão os quais favorecem a formação de material particulado mais finos. Processos físicos, como a ressuspensão de poeiras de solos, causado inclusive pelo processo de mecanização agrícola, transferem principalmente partículas grossas para a atmosfera. Com base nestas afirmações, a determinação da composição de material particulado em diferentes faixas de tamanho é importante para se conhecer o tipo e a intensidade das fontes de emissão que atuam em uma determinada região.

O objetivo principal deste projeto foi avaliar a qualidade da atmosfera de Araraquara, localizada na região central do Estado de São Paulo. Através da amostragem de poluentes particulados realizada no interior do Campus da Faculdade de Ciências e Letras da Unesp de Araraquara, considerando as mudanças eminentes no período de análise comparando com dados anteriores ao processo de mecanização e expansão da agroindústria de uma importante região agroindustrial do interior do Estado de São Paulo. Foram analisados a concentração, distribuição de tamanho do material particulado e a composição de elementos traço presentes neste poluente, bem como a distribuição desses elementos em função do tamanho das partículas.

\section{MATERIAIS E MÉTODOS}

O estudo foi desenvolvido na cidade de Araraquara localizada na região central do Estado de São Paulo. A amostragem de material particulado foi realizada na estação de monitoramento no interior do Campus da Faculdade de Ciências e Letras da Unesp de 
Araraquara a qual situa-se a oeste da cidade a $1 \mathrm{~km}$ do limite urbano e aproximadamente $4 \mathrm{~km}$ a sudoeste do centro da cidade, em coordenadas geográficas 21\%47'37" (latitude sul) e 48¹0'52" (longitude oeste), com uma altitude média de 646 metros em relação ao nível do mar. A amostragem do material particulado foi realizada utilizando-se um monitor ótico DataRam e o amostrador Impactador de Cascata de oito estágios. Para amostragem ambiental com o DR4 foi utilizada a sonda ominidirecional e pré-coletor para efetuar o diâmetro de corte para partículas menores que $2,5 \mu \mathrm{m}$.

Para o estudo comparativo da distribuição de tamanho de partícula com as concentrações dos íons presentes nas amostras foram analisados os filtros dos oito estágios do impactador correspondente as frações de distribuição de tamanho $(0$ a $10 \mu \mathrm{m})$. Para extração dos íons solúveis no material particulado foi feita a solubilização das espécies em água. Cada filtro foi solubilizado em $0,5 \mathrm{~mL}$ de álcool isopropílico para minimizar o caráter hidrofóbico e posteriormente $9,5 \mathrm{~mL}$ de água deionizada e acondicionados em tubo falcon de $50 \mathrm{~mL}$. As soluções foram submetidas à determinação cromatográfica. As espécies iônicas analisadas foram: sódio $\left(\mathrm{Na}^{+}\right)$, amônio $\left(\mathrm{NH}_{4}^{+}\right)$, potássio $\left(\mathrm{K}^{+}\right)$, magnésio $\left(\mathrm{Mg}^{2+}\right)$, cálcio $\left(\mathrm{Ca}^{2+}\right)$, fluoreto $\left(\mathrm{F}^{-}\right)$, acetato $\left(\mathrm{H}_{3} \mathrm{CCOO}^{-}\right)$, formiato $\left(\mathrm{HCOO}^{-}\right)$, cloreto $\left(\mathrm{Cl}^{-}\right)$, nitrito $\left(\mathrm{NO}^{2-}\right)$, nitrato $\left(\mathrm{NO}^{3-}\right)$, fosfato $\left(\mathrm{PO}_{4}{ }^{2-}\right)$, sulfato $\left(\mathrm{SO}_{4}{ }^{2-}\right)$ e oxalato $\left(\mathrm{C}_{2} \mathrm{O}_{4}{ }^{2-}\right)$. As concentrações das espécies iônicas foram determinadas por cromatografia de troca de íons utilizando-se o cromatógrafo de íons Thermo Scientific ICS 5000.

\section{RESULTADOS E DISCUSSÕES}

Os dados coletados nos meses de novembro 2016, fevereiro e março de 2017 foram agrupados em gráficos para facilitar a comparação entre os diâmetros, umidade relativa, temperatura e concentrações das partículas coletadas durante o período de amostragem. A umidade relativa variou entre 20 e $64 \%$ nestes dias de amostragem. A Figura 1 apresenta os diâmetros referentes aos dias amostrados.

Figura 1 - Diâmetros das partículas referentes aos dias 25/11/16, 24/02/17 e 09/03/17.

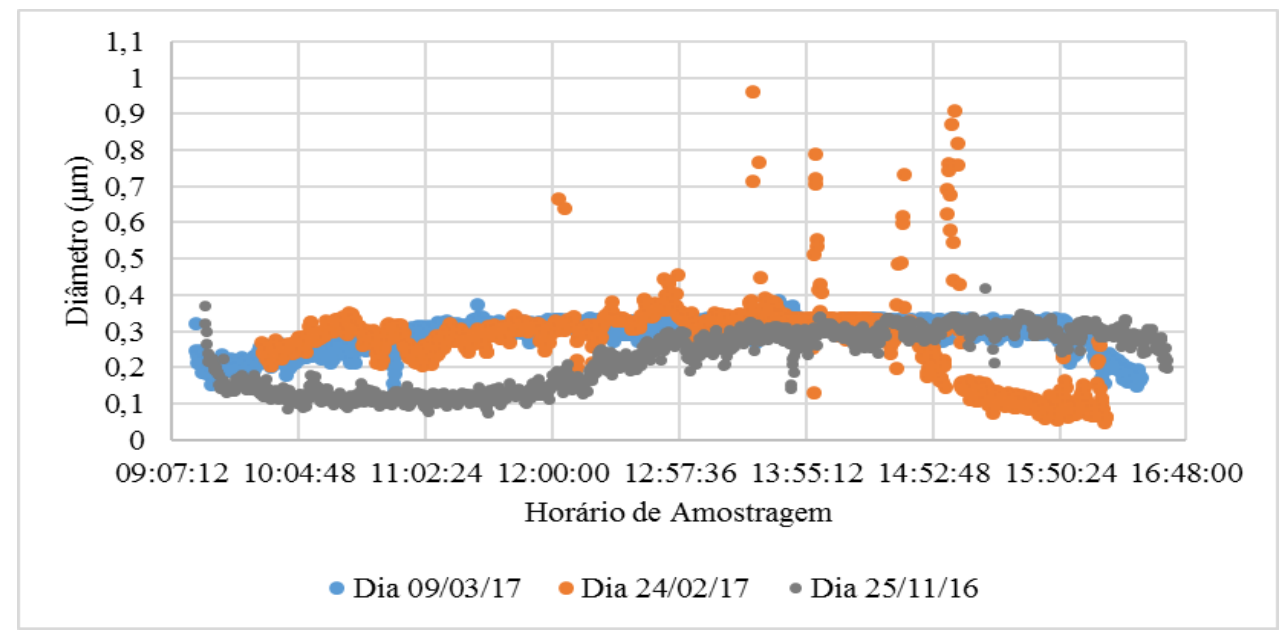

Observando a Figura 1 vemos que a maioria das partículas nos dias amostrados estavam entre as faixas de 0,1 a $0,4 \mu \mathrm{m}$. A distribuição de tamanho de partículas apresentou diâmetro menores que $0,05 \mu \mathrm{m}$ em alguns horários específicos. Na manhã do dia 25/11/16 e na tarde do 
dia 24/02/17 houveram partículas com os menores diâmetros, mesmo no dia de maior umidade relativa. A presença de partículas nesta faixa de diâmetro pode ter como fonte a queima de biomassa utilizada como combustível industrial ou mesmo a queima aberta de biomassa próxima a região amostrada. Na Figura 2 temos as concentrações em função do horário de amostragem para o dia 25/11/16.

Estes dados de concetração e distribuição de tamanho foram obtidos com o monior ótico e confirmados pelo impactador de cascata que apresentou maiores quantidade gravimétricas de partículas para as menores faixas de diâmetro.

Figura 2 - Concentrações das partículas em função do horário de amostragem.

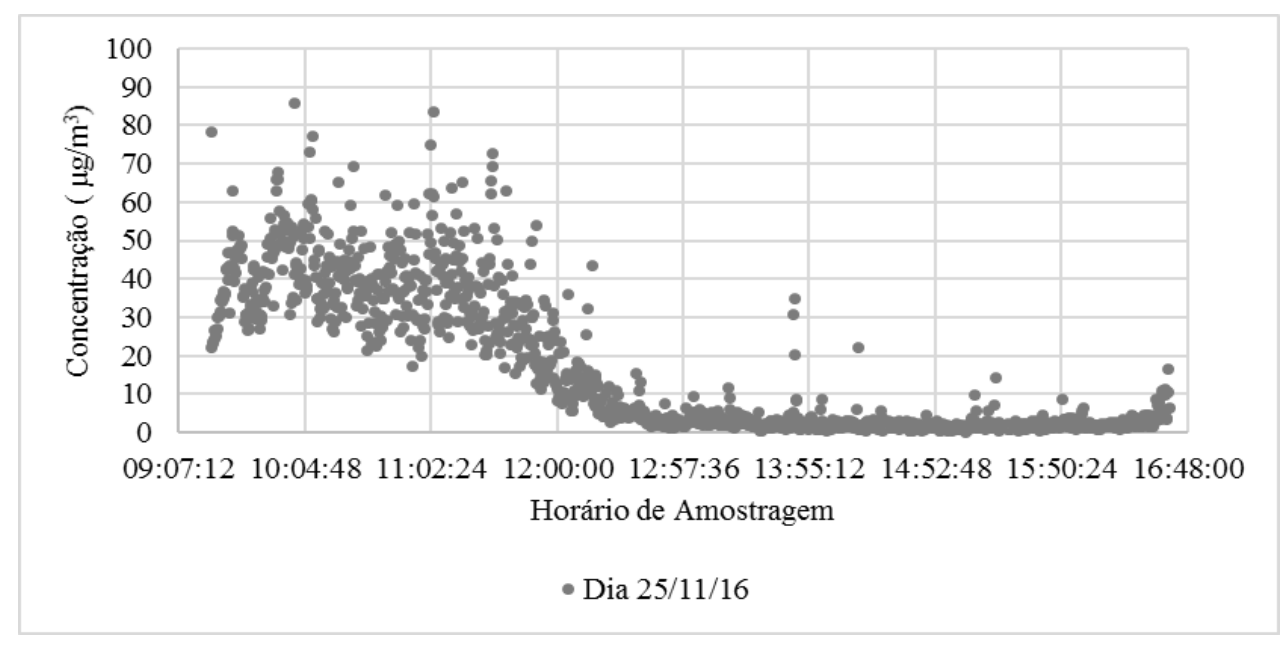

As maiores concentrações no dia 25/11/16 foram obtidas durante o período da manhã. Se analisarmos os dados das Figuras 1 e 2 percebemos que nos horários em que houveram maiores concentrações de partículas, estas tinham os menores diâmetros. Fortalecendo a hipótese de ter ocorrido a queima de biomassa durante este período, além deste diâmetro amostrado ser muito danoso à saúde. As Figura 3 e 4 apresentam as análises dos ânions e cátions presentes nos filtros utilizados no impactador de cascata com 8 estágios.

Figura 3 - Análise dos ânions presentes nos filtros de cada estágio do impactador de cascata.

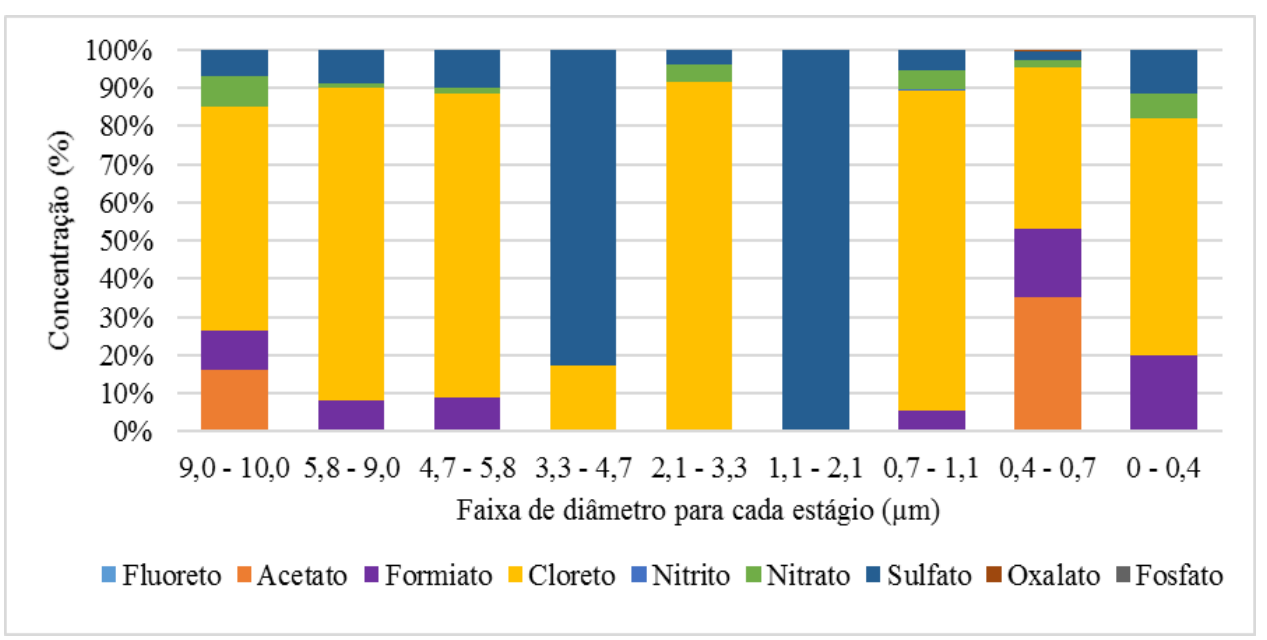


Figura 4 - Análise dos cátions presentes nos filtros de cada estágio do impactador de cascata.

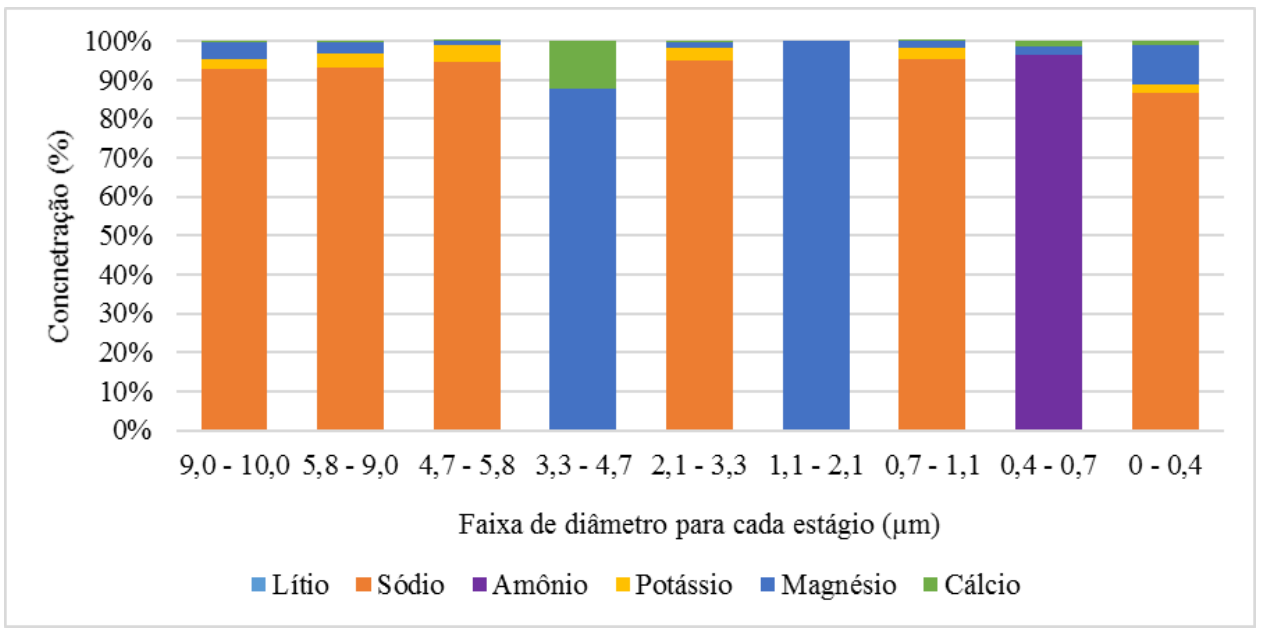

A partir das análises dos ânions presentes nos filtros dos diferentes estágios do impactador, evidenciou-se as maiores concentrações do ânion Cloreto, Sulfato, Formiato, Nitrato e Oxalato nos estágios com partículas com diâmetro menor que $1 \mu \mathrm{m}$. No trabalho de Souza, M.L.,2016 feitos na mesma região relatou que o nitrato e sulfato são componentes importantes dos aerossóis presentes na região de estudo e que a queima da cana-de-açúcar é uma fonte de gases e partículas liberados para a atmosfera. Na estação úmida de verão, altas emissões de amônia podem ser atribuídas à adição de fertilizantes nitrogenados a solos úmidos. Também a influência das queimadas de cana-de-açúcar sobre as concentrações das principais espécies $\mathrm{K}^{+}, \mathrm{NO}^{3-}, \mathrm{SO}_{4}{ }^{2-}$ no aerossol na fração de tamanho de $0,49 \mu \mathrm{m}$. No trabalho de Souza a concentração de $\mathrm{K}^{+}$medido no dia influenciado pela queima de biomassa era de cerca de quatro vezes maior em comparação com o dia que não sofreu impacto da queimada, enquanto que as concentrações de $\mathrm{NO}^{3-} \mathrm{e} \mathrm{SO}_{4}{ }^{2-}$ eram cerca de 2 vezes maior no dia impactado. Em 2014 no período de entressafra fontes como indústria e trafégo de veículos contribuíram para a emissão de $\mathrm{SO}_{2}$. $\mathrm{O}$ íon cloreto na atmosfera possui como fonte o aerossol marinho quando associado ao sódio. Porém ele pode ser emitido por queima de biomassa e queima de combustíveis. É um dos componentes do solo e desta forma estar associado a emissões primárias. Na figura 4 vemos as concetrações de cátions e uma maior presença do sódio em quase todas as faixas de tamanho. $\mathrm{O}$ fosfato presente na atmosfera é proveniente de aerossóis primários resultado de solo com fertilizantes e queima de biomassa. Os íons $\mathrm{Ca}^{2+} \mathrm{e}$ $\mathrm{Mg}^{2+}$ são constituintes do solo e podem chegar a atmosfera como resultado de emissões primárias resultante de vento.

\section{CONCLUSÃO}

Dentre os dias amostrados encontrou-se as maiores concentrações de material particulado menores do que $0,05 \mu \mathrm{m}$ durante o dia $25 / 11 / 16$.

$\mathrm{Na}$ análise dos ânions obteve-se maiores concentrações de Cloreto, Sulfato, Formiato, Nitrato e Oxalato nos estágios com diâmetro menor que $1 \mu \mathrm{m}$. 
Na análise dos cátions obteve-se maiores concentrações de Sódio, Potássio, Magnésio e Amônio. Estes dados são característicos da queima de biomassa, o que sugere que tenha ocorrido queima de biomassa próximo a região onde esteva sendo feita a amostragem.

O aumento do uso da biomassa como material para produção de energia através de sua queima, torna importante os estudos sobre matérias particulados menores que $1 \mu \mathrm{m}$ e a composição iônica deste.

\section{REFERÊNCIAS}

ALLEN, A. G.; MACHADO, C. M. D.; CARDOSO, A. A. Measurements and modeling of reactive nitrogen deposition in southeast Brazil. Environmental Pollution, v. 159, p. 1190-1197, 2011.

COMPANHIA NACIONAL DE ABASTECIMENTO. Pesquisa de safras e informações geográficas da agricultura brasileira. Brasília, DF, [2016]. Descrição: 0205-série histórica de área plantada, produtividade e produçãocana-de-açúcar. Disponível em: <http://www.conab.gov.br/conteudos.php?a=1534\&t=2>. Acesso em: 10 out. 2015.

CHERUBIN, M. R.; FRANCO, A. L. C.; CERRI, C. E. P.; OlIVEIRA, D. M. da S.; DAVIES, C. A.; CERRI, C. C. Sugarcane expansion in Brazilian tropical soils-Effects of land use change on soil chemical atributes. Agriculture, Ecosystems and Environment 211 (2015) 173-184.

FRANÇA, DANIELA DE AZEREDO ET AL. Pre-Harvest Sugarcane Burning: Determination of Emission Factors through Laboratory Measurements. Atmosphere, São José Dos Campos, p.164-180, 15 fev. 2012.

IBRAHIM AL-NAIEMA, ARMANDO D. ESTILLORE, IMALI A. MUDUNKOTUWA A , VICKI H. GRASSIAN, ELIZABETH A. STONE. Impacts of co-firing biomass on emissions of particulate matter to the atmosphere. Fuel 162 (2015) 111-120

MÁRCIA AZANHA FERRAZ DIAS MORAES A,N , FABÍOLA CRISTINA RIBEIRO OLIVEIRA B , ROCIO A. DIAZ-CHAVEZ .Socio-economic impacts of Brazilian sugarcane industry. Environmental Development 16 (2015) 31-43.

PATRÍCIA LOPES DE OLIVEIRA; BERNARDINO RIBEIRO FIGUEIREDO; ARNALDO ALVES CARDOSO; RÔMULO SIMÕES ANGÉLICA. Trace elements in atmospheric particulate matter from an agro-industrial region in southeastern Brazil. Quím. Nova vol.36 no.4 São Paulo 2013.

R.C. URBAN, C.A. ALVES, A.G. ALLEN, A.A. CARDOSO, M.L.A.M. CAMPOS. Organic aerosols in a Brazilian agro-industrial area: Speciation and impact of biomass burning. Atmospheric Research 169 (2016) 271-279.

SOUZA, M. de L. Estudo da distribuição tamanho e composição iônica de aerossóis e seus efeitos na capacidade de nuclear gotas de nuvens. 2016. $154 \mathrm{f}$. Tese (Doutorado em Química Analítica) - Instituto de Química, Universidade Estadual Paulista Júlio de Mesquita Filho, Araraquara. 2016.

UNICA, 2015. A Dimensão do Setor Sucroenergético Mapeamento e Quantificação da Safra $2013 / 14$. 